\title{
IMPARCIALIDAD INFORMATIVA Y FÚTBOL EN LA TELEVISIÓN PÚBLICA. EL CASO DE LA TELEVISIÓN CANARIA*
}

\author{
Aníbal Mesa López \\ animelo@ull.es \\ José Luis Castilla Vallejo \\ jlcast@ull.es \\ Manuel E. González Ramallal \\ mramal@ull.es

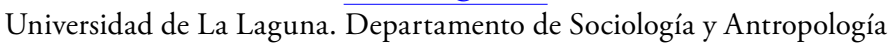

\section{RESUMEN}

Es habitual encontrar entre las aficiones una crítica velada de los desiguales tratamientos informativos que reciben sus equipos de fútbol. Este artículo centra esta cuestión en la realidad de las Islas Canarias e indaga sobre el tratamiento informativo que el principal medio de comunicación regional, la Televisión Canaria, da sobre los dos equipos de más tradición: la Unión Deportiva Las Palmas y el Club Deportivo Tenerife. Intentamos dar respuesta a la pregunta ¿existe equilibrio en la presentación de la información, o uno de los equipos tiene más preeminencia en este medio? Los resultados de esta investigación señalan un contexto de preocupación por el equilibrio en el que la Unión Deportiva Las Palmas goza de una mayor preeminencia.

PALABRAs Clave: fútbol, televisión pública, información, pleito insular, ética informativa.

\section{INFORMATION FAIRNESS AND FOOTBALL. \\ THE CASE OF THE TELEVISIÓN CANARIA}

\section{Abstract}

It is common to find among the supporters a veiled criticism of the unequal informational treatment that receives their own football teams. This article focuses this issue on the reality of the Canary Islands and investigates the informational treatment that the main regional media, the Televisión Canaria, gives about two teams of more tradition and football reference: Unión Deportiva Las Palmas and Club Deportivo Tenerife. We try to answer the question: Is there balance in the presentation of information, or one team has more media prominence? The results of this research indicate a context of concern for the balance where the Unión Deportiva Las Palmas enjoys greater prominence.

KEYWORDs: football, television, information, insular dispute, information ethics. 


\section{INTRODUCCIÓN}

Este artículo surge del continuo choque con un discurso cotidiano que señala una incomodidad hacia los medios de comunicación en general, y hacia los de carácter público en particular, fundamentalmente por ser incapaces de alcanzar un equilibrio a la hora de representar a nuestro grupo de pertenencia frente a otros. En diversos contextos y situaciones nos encontramos con la crítica de que determinados medios «nos tratan mal», o lo que es más común, «que tratan mejor al otro». Las alarmas identitarias se activan y se pone en juego el «nosotros-ellos» para denunciar que no se nos presta la misma atención que a los demás, al tiempo que se cuestiona la profesionalidad del medio en cuestión.

Este discurso, percibido por nosotros en un contexto exclusivamente regional, está de hecho muy relacionado con una crítica más amplia realizada dentro del Estado español, en el que las regiones periféricas han puesto el acento sobre el excesivo centralismo de los medios de comunicación de difusión estatal y en las dificultades de distribución de la producción mediática generada desde esos lugares. Como respuesta a esto, ya en los años ochenta, el desarrollo del Estado de las Autonomías sentó las bases para el nacimiento de un corpus mediático regional que cubriera las exigencias y necesidades de cada lugar, con la consiguiente proliferación de televisiones y radios autonómicas (Bustamante Ramírez, 2006; Riera, 2003; Palacio, 2001).

Estos nuevos medios, junto con las delegaciones regionales de la cadena pública estatal (Radio Televisión Española), pasaron a ser la garantía pública de representación mediática en cada autonomía, colocándose en el centro de la diana de la vigilancia identitaria de la audiencia. De este modo, el discurso del «nosotros-ellos» pasa a desarrollarse intensamente en el ámbito mediático regional. Unido a esto, el carácter público no hace más que aumentar la exigencia de unos espectadores que se saben legitimados para realizar demandas a unas estructuras sostenidas con el dinero de los contribuyentes.

Así, mientras se entiende que los canales comerciales se mueven dentro de términos mercantiles, hecho que modula el carácter de la crítica que se les realiza, determinados alineamientos de los medios públicos no son aceptados. Todo esto hace que la presión recibida por los medios autonómicos para mantener el equilibrio en la representación identitaria sea enorme.

Esta situación es especialmente visible en el mundo del deporte, en particular del fútbol, como espacio privilegiado de configuración del «nosotros-ellos». No decimos nada nuevo al afirmar que resulta un hecho cotidiano vincular la información deportiva emitida por algunos medios como favorecedora de un deporte, un equipo o un jugador frente a otros. Esta realidad es muy evidente a nivel estatal, tanto en el caso del fútbol frente a todos los demás deportes (Llopis Goig, 2006b;

* Este artículo ha sido previamente publicado en la revista Index Comunicación (vol. 6, núm. 1, 2016). Lo reproducimos aquí entendiendo que su carácter regional lo vuelve de especial interés para el ámbito geográfico que cubre esta publicación. 
González Ramallal, 2004a, 2004b) como en la histórica confrontación entre el Real Madrid Club de Fútbol y el Fútbol Club Barcelona (González Ramallal, 2014; Llopis Goig, 2006a; Ball, 2010).

La mayoría de las filias y fobias deportivas y mediáticas estatales se ubican dentro de este panorama, con medios afines a uno u otro equipo, siendo especialmente significativos los casos de la prensa deportiva de difusión estatal editada en Madrid (Marca y As) y Barcelona (Sport y Mundo Deportivo). A ello hemos de unir, además de programas radiofónicos deportivos nocturnos y de fin de semana, la proliferación de programas televisivos de debate (Punto Pelota, Futboleros, Tiki-Taka, El Chiringuito de Jugones) donde la cobertura informativa gira de manera constante en torno al eje Madrid-Barcelona. Además, hay que tener también en cuenta las diferencias que se dan en la atención informativa que un medio le da a un evento deportivo determinado en función de que posea o no sus derechos de emisión (Gallardo Parrón y Montes Vozmediano, 2015).

Como ya apuntamos, este fenómeno, en el que se estima que determinados medios de comunicación vuelcan su interés hacia uno o unos clubes determinados, se trasladó inmediatamente a los nuevos entes autonómicos. Las históricas rivalidades deportivas regionales pasaron así a desarrollarse en el plano mediático entre los partidarios, entre otros, del Barcelona y el Espanyol (Cataluña), Real Madrid y Atlético de Madrid (Madrid), Sevilla y Betis (Andalucía), Deportivo de La Coruña y Celta de Vigo (Galicia), Athletic de Bilbao y Real Sociedad de San Sebastián (País Vasco); que habitualmente consideran que sus equipos son maltratados desde el punto de vista informativo frente a los favorecidos vecinos y rivales deportivos.

En este estudio vamos a abordar el caso canario, en el que se presenta una histórica rivalidad entre la Unión Deportiva Las Palmas, equipo representativo de la isla de Gran Canaria, y el Club Deportivo Tenerife, representativo de la isla de Tenerife. Al igual que en los contextos que hemos explicado hasta ahora, es práctica común la crítica de los aficionados hacia una mayor atención al equipo rival por parte de los medios regionales. Ni unos ni otros están contentos.

En especial la Televisión Canaria, el ente público autonómico, que se encarga de la actualidad y, hasta la temporada 2014/2015, de la retransmisión de la práctica totalidad de los partidos de ambos clubes, es la que se encuentra en el punto de mira y recibe las mayores críticas. Por esa razón, nuestro análisis se va a centrar en la información deportiva emitida por dicho canal sobre los dos equipos en los informativos de mayor audiencia, en un momento en el que ambos compartían protagonismo en la segunda categoría del fútbol español, la Segunda División. Todo ello contextualizado dentro de la lucha entre las dos grandes islas por alcanzar la hegemonía política en el archipiélago, el llamado pleito insular.

Así, el objetivo principal de este trabajo es dilucidar de un modo sistemático, y huyendo de los discursos y diatribas apasionadas, qué y cuánto hay de verdad en las rivalidades deportivas mediáticas de carácter regional manifestadas por los aficionados; y qué y cuánto hay de discurso implícita o explícitamente interesado de refuerzo identitario regional o local por parte de los medios. Como objetivo secundario pretendemos conocer los protocolos, dinámicas y procedimientos que se dan a la hora de presentar la información deportiva en un medio público de 
carácter regional. Abordar una investigación de este tipo nos permitirá conocer en detalle los desafíos a los que se enfrentan los medios públicos autonómicos a la hora de trasladar una información con efectos identitarios, siempre expuesta a la particular interpretación de los espectadores.

Nuestra principal hipótesis de trabajo es que la cobertura informativa tiende a cubrir de un modo similar a los dos equipos y, por lo tanto, se aleja del discurso parcial de los aficionados, que perciben la existencia de un trato de favor interesado hacia el equipo rival. La consecuencia de esto en términos identitarios sería el interés por parte del medio de transmitir y reforzar una identidad más regional que local.

Pasaremos ahora a contextualizar el escenario del pleito insular, para a continuación presentar las características básicas del medio de comunicación analizado, así como sus principales dilemas y cuestionamientos. Esto dará a pie a la formulación de las preguntas que intentaremos contestar con este trabajo. Posteriormente explicaremos el enfoque y los instrumentos metodológicos utilizados, pasando finalmente a la presentación y análisis de los datos obtenidos.

\section{Pleito insular, COMPeTENCIA Mediática y Fútbol}

El denominado pleito insular en Canarias ha sido un fenómeno desigualmente estudiado, pero sobre el que han corrido innumerables ríos de tinta mediática y política (Guimerá Peraza, 2011; Monzón y Santana, 1988). Forma ya parte de la historia social del territorio la confrontación entre bloques históricos interclasistas y pugnas diversas por la hegemonía territorial competida entre las dos islas centrales del archipiélago (Tenerife y Gran Canaria).

En esencia podemos considerar que el denominado "pleito insular», constituye una lucha por la hegemonía política y económica de los bloques de poder de Gran Canaria y Tenerife [...]. En la primera isla, parece que los intereses están aunados en su capital, Las Palmas de Gran Canaria; pero en la segunda hay diversidad de aspiraciones, por un lado está La Laguna con su aristocracia, enfrentada a Santa Cruz y la Orotava con sectores aristocráticos, frente al Puerto de la Cruz; esto coloca a Las Palmas en una posición más favorable ante la cuestión por producirse unas voluntades convergentes entre aristocracia agraria y burguesía comercial (Monzón y Santana, 1988: 22).

Por supuesto, los medios de comunicación no han quedado al margen de esta disputa, como lo atestiguan históricamente tanto la prensa escrita y la radio, como los nuevos actores mediáticos televisivos de emisión estatal, regional y local (Acirón Royo, 1998).

Hacer un recorrido por la extensión de esferas de la vida social en las que este fenómeno se despliega resultaría imposible aquí, pero, aproximándonos al problema, la historia de la confrontación se centra en la ubicación de la capitanía y el mando militar; la competencia por las sedes de las instituciones estatales y regionales; la confrontación por las inversiones territoriales; las demandas de financiación 
unilaterales a la Unión Europea y al Gobierno central; el histórico conflicto por las universidades; la competencia por la hegemonía de las élites de los partidos y la procedencia de nacimiento del liderazgo; etc.

Esto no son más que muestras de cómo la ideología de la pugna liderada por bloques de interés ha cristalizado en el conjunto social configurando un, llamémoslo así, «espectro» que de cuando en cuando es renovado en función de intereses estratégicos: el espectro del pleito insular. En tal escenario, el fútbol y su recreación social no han quedado al margen de estas disputas. De hecho, es con frecuencia uno de los lugares en los que se canaliza de forma más interesante este belicismo civilizatorio ${ }^{1}$. Esto es así porque es en el fútbol donde la fusión entre pasión emocional y reglas del juego conducen a la sociedad por la senda de ensamblar norma y emoción. De esta manera, la Unión Deportiva Las Palmas (en adelante, UDLP) y el Club Deportivo Tenerife (en adelante, CDT) configuran uno de los escenarios en los que el theatrum mundi de la vida regional se desenvuelve.

En ocasiones, por supuesto, estos bloques en confrontación establecen también alianzas basadas en el interés común o en la lucha contra un enemigo exterior. Una política de exportación puede convenir a las élites en su conjunto tanto como una política fiscal que subvenciona las importaciones, por ejemplo. Y sin lugar a dudas, el denominado «hecho insular», con su retórica oscura (coste de insularidad, ultraperiferia, sentimiento de inferioridad trufado con retóricas de orgullo, incomprensión respecto a la canariedad, etc.), articula el discurso convergente a potenciar el enriquecimiento de sectores que dependen tanto del turismo como de exportaciones agrarias, subvenciones y recursos públicos.

Este pacto-alianza también tiene su correlato en el fútbol. El intento de equilibrio en la aportación de fondos públicos a estos dos clubes deportivos solo se sostiene si la lógica de la aportación es regional. Los cabildos y otras administraciones locales han tendido a jugar un papel de apoyo incondicional a sus clubes de referencia insular. Solo en caso de que una de las dos entidades esté en riesgo la ayuda regional se antepondrá a la lógica del equilibrio.

En términos mediáticos ocurre algo parecido. Mientras que las televisiones locales y las radios trabajan para cada uno de los equipos de fútbol mezclando información con propaganda y animando a sus audiencias locales a apoyar a su club, las televisiones regionales han de hilar más finamente ante la histórica rivalidad del pleito insular y ante la rivalidad futbolística. El exquisito trato y la equivalencia que reciben ambos clubes de las televisiones estatales en sus informativos de edición regional dan idea de la delicadeza política con la que se manejan estos temas ${ }^{2}$. Pero si hay un medio en particular que se encuentra bajo el escrutinio de la

${ }^{1}$ Para una revisión del concepto de proceso civilizador puede consultarse Elias (1989). Para una revisión de la relación entre proceso civilizador y deporte puede consultarse Elias y Dunning (1992).

2 Sin embargo, sí se produjeron problemas durante la implantación de la delegación regional de la Televisión Española en Canarias, generando lo que Guillermo Aguado denomina «desequilibrio informativo regional» a favor de Gran Canaria. Esto fue debido a que el centro de producción se situó 
audiencia en relación con el «espectro» social anteriormente descrito, esa es la Televisión Canaria (en adelante, TVC).

El proyecto de creación de una televisión pública canaria nació en 1984 bajo el amparo de la Ley de la Comunidad Autónoma de Canarias relativa a la Radiodifusión y Televisión Canaria. Sin embargo, no fue hasta 1997 cuando se constituyó el Consejo de Administración, y hasta 1998 cuando se adjudicó por medio de concurso público la realización y producción de la programación. Esta, junto con la gestión publicitaria, fue asignada a la Productora Canaria de Televisión Canaria (PCTV), participada al $40 \%$ por la empresa de comunicación Grupo Prisa. Finalmente, las emisiones comenzaron el 21 de agosto de 1999, eligiendo para el estreno el partido de fútbol de máxima rivalidad regional: UDLP vs. CDT. En el año 2000 la TVC inaugura sus nuevos centros de producción en las dos islas capitalinas (RTVC.es, 2014).

Desde el eslogan empresarial inicial, "la nuestra», hasta el actual «esto es Canarias", la TVC ha sido para la audiencia el rostro televisado del Gobierno de Canarias. Quizá por ello convive con el «espectro» del pleito insular, preocupada por crear unidad aun a fuerza de socavar sus bases narrativas. Por supuesto, en el tratamiento del fútbol, dada su relevancia como fenómeno socioregional, tiene por misión mantenerse escrupulosamente al margen de tales disputas. Esto sitúa al medio entre "la espada" evaluadora de la observancia de la audiencia aficionada $\mathrm{y}$ «la pared» de la necesidad de conquistar nuevas cotas de audiencia dada la crisis fiscal del Estado y, particularmente, de la Administración autonómica. Uno de los máximos responsables de la sección de deportes de la TVC (ver metodología) confirma esta apreciación:

Es verdad que las audiencias nos tiranizan como canal televisivo y nuestro objetivo es tener la mayor audiencia posible [...], pero también tenemos la responsabilidad de ser el lugar donde se pueda ver a los principales equipos, de fútbol y baloncesto principalmente, y donde se pueda ver el resto del deporte que se desarrolla en las islas. Si no fuera por la TVC habría mucha gente que no se entera de que va a empezar una copa de la reina de voleibol o que en El Hierro se hace una maratón. ¿Eso es espectáculo? Probablemente no, pero como medio público estamos obligados a mostrar la realidad del deporte en todas las islas ${ }^{3}$.

Hablemos primero de la pared. La TVC se encuentra como medio de comunicación bajo el dominio de relaciones político-mercantiles en el marco general de una regulación abierta del Estado dentro de una democracia formal. El juego de relaciones sociales, políticas y económicas en el marco de una sociedad neoliberal con altas dosis de mercantilización coloca a los medios públicos ante el ineludible recorte

exclusivamente en esa isla durante los primeros ocho años de vida de la delegación, entre 1964 y 1972. Este es el primer antecedente de disputa territorial y televisión en el archipiélago (Aguado, 1994).

${ }_{3}$ Responsable de la sección de deportes de la TVC. Entrevista realizada por los autores, 29 enero 2015. 
de fondos gubernamentales y la necesidad de sentar las bases de la sostenibilidad económico-financiera, al tiempo que se ven presionados para lograr más audiencias.

Si hacemos caso a la tesis de Kapuscinski de que «el mundo de los negocios descubre de repente que la verdad no es importante, y que ni siquiera la lucha política es importante: que lo que cuenta, en la información, es el espectáculo. Y, una vez que hemos creado la información-espectáculo, podemos vender esta infor-

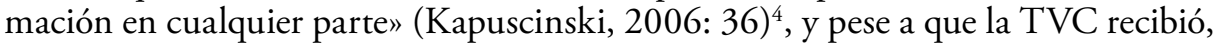
en el año 2015, 38,2 millones de euros de las arcas de la Administración regional (Montero, 2014) , una fuerza lo impele a ganar audiencias y a competir con otros medios públicos y privados. Esta encarnizada lucha mediática está empujando a los modelos televisivos a desechar los mecanismos de autorregulación, los comités deontológicos, los defensores del televidente o los principios de edición, y a colocar en el lugar central la información-espectáculo.

Este forzamiento a espectacularizar la información se ha extendido a lo largo y ancho de la emisión televisiva, pero aún más si cabe en el deporte y particularmente en el fútbol. El fútbol, al ser un espectáculo de masas en sí mismo, y dado el gran interés que muestra la audiencia en él (López González, Guerrero Solé y Larrea, 2014), proyecta esta cultura mainstream que se traduce en un pastiche de información, análisis, seguimiento al minuto, tuits, chismes, rumores, difamaciones, declaraciones, etc. Como sugiere Lluis Bassets, «en el postperiodismo es noticia todo lo que colgamos en la red y alguien considera que es noticia [...] se disuelve así la noción de interés general a favor de los intereses particulares» (Bassets, 2013: 184) ${ }^{6}$.

Así, las fronteras entre lo público y lo privado, la información veraz y el rumor, la noticia y el scoop o exclusiva, la información elaborada y la información casual, se diluyen progresivamente.

La pared, por tanto, fuerza a la TVC a hacerse un hueco en la competencia bajo esta lógica de la mercadotecnia y la evolución mediática. Cualquier dinámica dirigida a trabajar en un terreno de juego distinto (desapasionar, restringirse a lo estrictamente informativo, separar información de propaganda, etc.) conduce al medio por el camino de la "deseconomización", la irrelevancia informativa, la burocratización editorial y la neutralidad emocional provocada por el miedo al «espectro» del pleito. Las audiencias, hoy más autónomas y con más recursos digi-

${ }^{4}$ Sobre esta cuestión también puede consultarse Riera (2003); Debord (1976); González Radío (1997).

5 Sin embargo, debe tenerse en cuenta que el ente público ha estado sometido a importantes restricciones presupuestarias desde el inicio de la crisis económica. Mientras en 2008 la dotación alcanzó su máximo histórico con 66984 241€, en 2013 se quedó en $33374079 €$ (Gobierno de Canarias, 2014).

${ }^{6}$ Este desplazamiento afecta también a otras esferas de la cultura futbolística, como puede verse en los autores (2014).

${ }^{7}$ Por deseconomización del medio entendemos la autorregulación articulada para contener la información en formatos desapasionados y autocontenidos, bajo el principio de responsabilidad y equilibrio territorial. 
tales, convierten en irrelevante dicho producto, lo que lleva en general a las empresas periodísticas a un desafío completo de sus estructuras.

Pero vayamos ahora con la espada. La espada aquí la representa la audiencia observante y demandante de eventos. Pero la audiencia canaria está forjada en una fragua muy particular, la del pleito insular. En la TVC son perfectamente conscientes de ello: «[el pleito insular] está presente. Nosotros no somos Telecinco, somos la TVC, y eso está presente en nuestra sociedad " ${ }^{8}$. La pasión deportiva de los canarios se desenvuelve en el fútbol bajo la luz del «espectro», y es precisamente esa luz la que no quieren encender ni el Gobierno de Canarias ni su televisión.

Por esto, en cuestión de fútbol regional, la consigna es la «purificación política», es decir, separar al fútbol de cualquier acontecimiento o tratamiento informativo que decline la balanza hacia alguno de los dos contendientes fundamentales y pueda estar asociada a cualquier interpretación política. En este sentido, existe una herramienta internacional a través de la que el medio podría legitimar la búsqueda de ese objetivo. La Directiva 97/36/CE, del Parlamento y el Consejo Europeo, conocida como Televisión sin Fronteras, articula un reclamo ético y deontológico que centra el principio de responsabilidad pública de los modelos de regulación:

Así como otras [...], como la Ley 25/1994 (modificada parcialmente por la Ley 22/1999) que traslada al ordenamiento jurídico español la Directiva 97/36/CE, conocida como Televisión sin Fronteras. El contenido de estos principios inspiradores es básicamente el mismo y destaca que su actividad se inspirará en:

a) La objetividad, veracidad e imparcialidad de las informaciones.

b) La separación entre informaciones y opiniones, la identificación de quienes sustentan estas últimas y su libre expresión, con los límites marcados en el artículo 20 de la CE.

c) El respeto al pluralismo político, religioso, social, cultural y lingüístico.

d) El respeto al honor, la fama, la vida privada de las personas y cuantos derechos y libertades reconoce la CE.

e) La protección de la juventud y la infancia.

f) El respeto a los valores de igualdad recogidos en el artículo 14 de la CE (Aznar, 2005: 114).

Pero las audiencias son inquisitivas. Sus pasiones tienden a modular los juegos de interpretación y a establecer sentencias sobre el trabajo de los medios, y particularmente sobre medios que paga la propia audiencia con sus impuestos. Precisamente por ello, el runrún sobre la TVC en cuestiones futbolísticas es el tratamiento desigual entre los dos grandes clubes. Los aficionados de Gran Canaria tienden a ver un tratamiento más favorable al CDT, mientras que los de Tenerife tienden a ver un sesgo informativo que favorece a la UDLP.

${ }^{8}$ Responsable de la sección de deportes de la TVC. Entrevista realizada por los autores, 29 enero 2015. 
Esta percepción coloca al medio evaluado en situación de insatisfacción permanente de sus consumidores y sitúa al Gobierno ante la supervisión que demanda purificar el fútbol de cualquier relación con lo político. La ideología del victimismo entre aficiones, que conecta profundamente con la ideología victimista tan propia de la identidad canaria (Sánchez, 1983; Aguilera Klink, 2004), llora la ausencia de una demanda insatisfecha: «No nos tratan con respeto puesto que al otro lo tratan mejor».

Cuando se analizan los informativos la impresión que dan es de desapasionamiento burocrático. Las emociones solo se pueden hacer públicas cuando están referidas a los dos conjuntos por igual o en algún acontecimiento de uno de ellos no competido con el otro, si es que esta circunstancia puede darse en un contexto de rivalidad deportiva entre dos clubes. El cálculo de la presencia en la información, así como el orden de aparición, deben ser medidos al segundo. La estrategia que neutraliza la lógica del victimismo es la edición neutra, la emisión carente de afecto y el rigor informativo que no pone en el centro del cálculo la relevancia de la noticia sino la estrategia de la compensación.

Pero en cualquier caso la resultante es siempre incómoda, como si el vaso jamás se pudiera llenar. Por calculada que esté la edición y por compensada que esté la realización del informativo, las audiencias-aficiones jamás encuentran lo que buscan: propaganda a su favor. Y mucho menos propaganda a su favor en relación con su adversario fundamental.

Entre mercado, Gobierno y audiencias está la TVC con un proyecto difícil de ejecutar por contradictorio. Purificar el fútbol, ganar audiencias, satisfacer a los aficionados, ser sostenible económicamente. Pero ¿efectivamente hay un tratamiento informativo equilibrado entre el CDT y la UDLP? ¿El trabajo de los informativos de la TVC ofrece razones para la ideología del victimismo en un sentido u otro? ¿La purificación tiene éxito? ¿El equilibrio informativo se consigue? ¿Cómo afectó el derbi canario al tratamiento informativo? Los datos que hemos obtenido en este estudio pueden revelarnos parte de esta compleja tesitura.

\section{METODOLOGÍA}

Para estudiar el problema que nos ocupa hemos optado por desarrollar un análisis de contenido desde una perspectiva cuantitativa. Para conocer en detalle las pautas y tendencias en el proceso de información deportiva del medio analizado utilizamos el instrumento empleado en González Ramallal (2004b: 211-235; descrito más adelante), adecuándolo al medio televisivo y a los objetivos específicos que se pretenden en este artículo. Como complemento a los datos cuantitativos obtenidos con ese instrumento, llevamos a cabo una entrevista estratégica y en profundidad con uno de los máximos responsables de la gestión del área deportiva del ente televisivo.

9 Un derbi es, según la Real Academia Española, un «encuentro, generalmente futbolístico, entre dos equipos cuyos seguidores mantienen permanente rivalidad». 
La información deportiva objeto de nuestro interés fue aquella emitida por la TVC relacionada con la UDLP y el CDT en el año 2014. Ambos clubes de fútbol son los más representativos de Canarias (ver tabla 1). Tomamos como referencia los programas informativos Telenoticias 1 y Telenoticias Fin de Semana (de 14:30 a 15:15 aproximadamente y de 14:30 a 15:00 aproximadamente, respectivamente) y los informativos específicamente deportivos TN Deportes 1 y TN Deportes 1 Fin de Semana (de 15:15 a 15:30 aproximadamente y de 15:00 a 15:15 aproximadamente, respectivamente). Estos informativos, los de mayor audiencia con los que cuenta el medio $^{10}$, se producen, en la franja horaria analizada, de lunes a viernes en la redacción de Tenerife y el fin de semana en la de Gran Canaria.

\begin{tabular}{lcc}
\hline \multicolumn{4}{c}{ TABLA I. FICHA TÉCNICA DE LOS CLUBES } \\
\hline UDLP & CDT \\
\hline Fundación & 1949 & 1922 \\
\hline Estadio (capacidad) & $\begin{array}{c}\text { Gran Canaria } \\
(31250)\end{array}$ & $\begin{array}{c}\text { Heliodoro Rodríguez López } \\
(22699)\end{array}$ \\
\hline Temporadas en Primera División & 31 & 13 \\
\hline Temporadas en Segunda División & 28 & 38 \\
\hline Temporadas en Segunda B & 6 & 8 \\
\hline Temporadas en Tercera División & 0 & 3 \\
\hline Mejor clasificación en Primera División & $2 .^{\circ}(1968-1969)$ & 5. ${ }^{\circ}$ (1992-1993) \\
\hline Mejor clasificación en Copa del Rey & Finalista (1977-1978) & Semifinalista (1992-1993) \\
\hline Clasificación histórica en Primera División & $19 .^{\circ}$ & 27. ${ }^{\circ}$ \\
\hline $\begin{array}{l}\text { Fuentes: Liga de Fútbol Profesional [web en línea] <http://www.lfp.es/> [consulta: 17-01-2015]; Club Deportivo Tenerife [web en línea] <http:// } \\
\text { www.clubdeportivotenerife.es/default.asp> [consulta: 18-01-2015]; Unión Deportiva Las Palmas [web en línea] <http://www.udlaspalmas.es/> }\end{array}$ &
\end{tabular}

Los datos recogidos y analizados corresponden a 22 días, distribuidos en dos períodos de tiempo: del lunes 24/03/2014 al domingo 06/04/2014, ambos inclusive (14 días en total); y del lunes 05/05/2014 al lunes 12/05/2014, ambos inclusive (8 días en total). La razón de contemplar un período específico posterior se debió a la pretensión de cubrir la información deportiva generada antes y después del derbi canario disputado el sábado 10/05/2014. Entendíamos que durante ese período el seguimiento al CDT y a la UDLP sería mayor de lo habitual, circunstancia que nos iba a permitir contrastar algunos de los datos inicialmente recabados.

10 Según datos proporcionados por la cadena, en el año 2016 TN Deportes 1 mantiene un $13,1 \%$ de cuota de pantalla, superior al $8,9 \%$ de la segunda edición. Por su parte, TN Deportes 1 Fin de Semana llega hasta un 12,6\%, también por encima de la segunda edición, que se sitúa en el 10,4\%. En cuanto al informativo Telenoticias 1 su audiencia llega hasta el 17,6\%, frente al inferior 11,6\% de la segunda edición. Por último, Telenoticias 1 Fin de Semana se sitúa en el 16,3\% de cuota de pantalla, mientras que la segunda edición logra el $12 \%$. 
Seleccionamos dos semanas que consideramos «tipo», en el sentido de que el centro informativo fuese la competición deportiva misma (Segunda División española) y el seguimiento de la actualidad fuera «normal» (en el sentido durkheimiano de lo frecuentemente estadístico), sin que otros eventos deportivos o circunstancias particulares en alguno de los equipos (cambio de entrenador, elección de un nuevo Consejo de Administración, crisis deportiva y/o económica, incidentes con aficionados, etc.) pudieran distorsionar la regularidad perseguida.

Buscamos también un período de tiempo en el que pudiésemos reducir la incidencia que determinados efectos del calendario futbolístico y de la clasificación deportiva pudiesen tener sobre el tratamiento de las informaciones por parte del medio, en el sentido de ofrecer una mayor cobertura a uno u otro club. En concreto nos referimos al «efecto localía» (que un equipo juegue más partidos como local que el otro, circunstancia que permitiría al medio una mejor y mayor accesibilidad a la hora de cubrir la información del equipo local) y al «efecto clasificatorio» (excesiva diferencia en la clasificación entre los equipos, lo cual podría hacer que el medio prestase más atención en función de este criterio $\left.{ }^{11}\right)$.

Así, en el período analizado la UDLP jugó cinco partidos, dos como local y tres como visitante, y el CDT otros cinco, tres como local y dos como visitante. Los dos equipos estaban en posición de play-off de ascenso a Primera División y la mayor diferencia registrada entre ambos se produjo tras el derbi (60 puntos la UDLP, tercera en la clasificación, y 54 el CDT, séptimo clasificado).

En total se registraron, codificaron y analizaron 202 noticias o unidades de información deportiva ${ }^{12}$ en una matriz de datos en Excel con las siguientes variables examinadas:

- Orden cronológico de presentación de las noticias: el orden de presentación nos marca una jerarquía en la preeminencia que se les da a las noticias de uno u otro club, siendo de especial relevancia aquellas que aparecen en el sumario del informativo generalista y al inicio del informativo específicamente deportivo, como luego veremos.

- Duración: tiempo de duración de la noticia.

${ }^{11}$ Nuestro entrevistado nos confirmó posteriormente que el orden clasificatorio no funciona como criterio a la hora de organizar la información, aunque sí lo había hecho en etapas anteriores del medio.

12 «La unidad de información deportiva [...] es una unidad portadora de información que alude al hecho, suceso o referente del cual dan cuenta los medios de comunicación y viene establecida en la mayoría de los casos por la propia fuente de información. Por ejemplo, [...] cada una de las noticias deportivas o entrevistas que se transmiten en un programa de radio o televisión y que se marcan por una pausa; cada una las fotografías e imágenes relacionadas con la actividad deportiva que se muestran en televisión, etc. Dicha unidad de información deportiva adquiere sentido pleno al referirse (necesariamente) a un acontecimiento deportivo determinado (un partido de fútbol o de balonmano, una carrera ciclista, un mundial de natación, un torneo de tenis, los resultados de la Liga de baloncesto, etc.), al cual siempre se asocia, al menos, una unidad de información deportiva» (González Ramallal, 2004b: 218). 
- Acompañamiento de la noticia con imágenes y duración de las mismas: se valora la importancia de la información visual, ya sea como valor testimonial, como refuerzo de la información verbal o como elemento central de la información. Se registra el tiempo en el que la noticia se acompaña de imágenes.

- Actor o actores protagonistas de la noticia: son los sujetos que protagonizan la acción de la noticia emitida. La unidad de información deportiva puede constar de uno o más actores protagonistas. Si existe más de un protagonista se anotan los dos primeros en orden a la atención (espacio y tiempo) que el medio les dedica. En este apartado se registra también la categoría -federación, club, directivo, entrenador, futbolista, árbitro, aficionados, medios de comunicación, instalaciones deportivas, otros- y el club de pertenencia, si lo hubiere, del actor o actores en cuestión.

- Actor o actores mencionados en la noticia: son aquellos actores que, sin ser sujetos protagonistas de la noticia, son mencionados en ella por estar asociados de alguna manera al actor o actores principales. Se han registrado hasta dos actores secundarios, también con su correspondiente categoría y filiación a club.

- Actores protagonistas de las imágenes emitidas: se inventariaron hasta dos actores protagonistas de las imágenes que acompañan a la noticia, en función del orden y el tiempo de exposición. También se registra su correspondiente categoría y filiación a club.

Una vez sintetizadas, ordenadas y estructuradas las noticias a partir de la matriz de datos, llevamos a cabo un análisis cuantitativo y descriptivo del contenido de la información deportiva sobre el CDT y la UDLP, en base a la frecuencia de aparición de los elementos registrados en ella. El mayor y mejor conocimiento de los protagonistas de las noticias, su orden de aparición, el tiempo dedicado, etc., nos permitió establecer un primer marco interpretativo de las características simbólicas y latentes de la información en base al contexto general de análisis que marca el objetivo planteado.

La entrevista personal en profundidad, realizada a uno de los máximos responsables de la gestión del área deportiva de la TVC, se llevó a cabo con posterioridad a los análisis iniciales que desarrollamos sobre las evidencias obtenidas cuantitativamente. Un análisis sociológico del discurso (Ruiz, 2009) nos permitió contrastar muchas de las interpretaciones e inferencias que habíamos realizado sobre los datos, y también nos sirvió para conocer y aclarar algunos de los protocolos, dinámicas y procedimientos que maneja el ente público regional a la hora de elaborar y presentar la información deportiva.

Para la entrevista se empleó un guion altamente estructurado con 31 preguntas distribuidas en tres grandes bloques temáticos: bloque orga nizacional y conocimiento del medio (11 preguntas), bloque deportivo y especificidades de la información deportiva (10 preguntas) y bloque deontológico, ético y de autorregulación del medio (11 preguntas). 


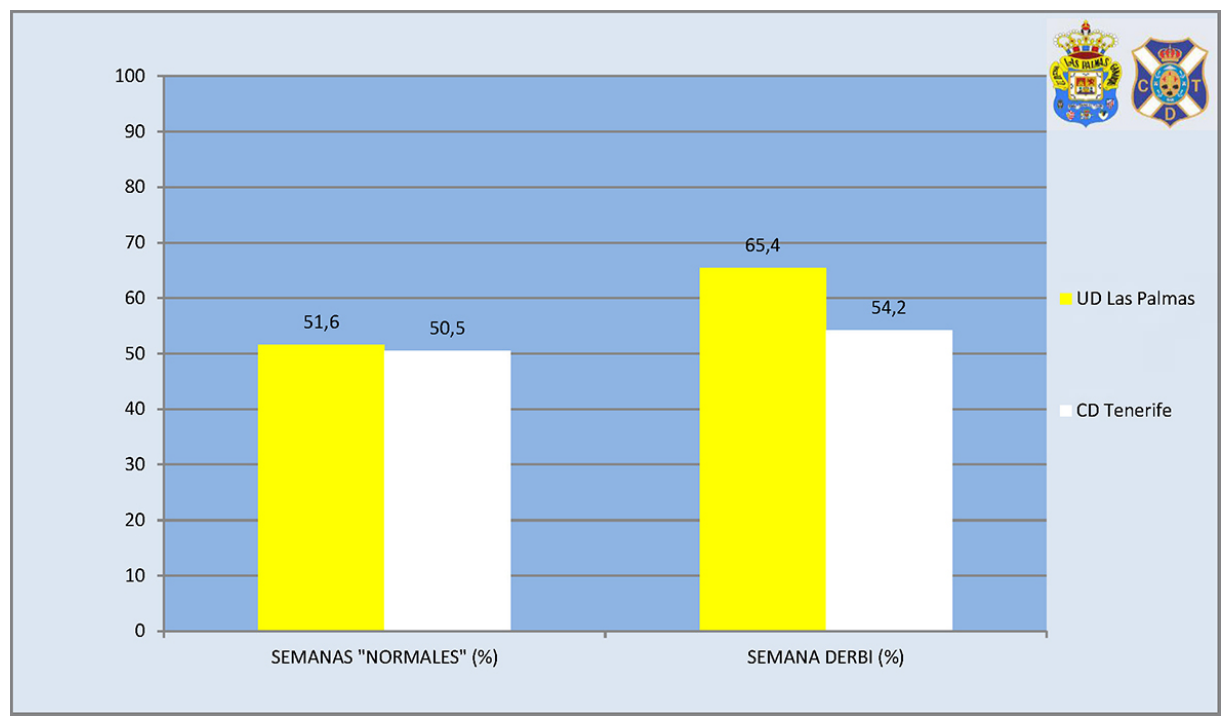

Número de noticias. N= 95 (semanas normales) y N= 107 (semana derbi). Elaboración propia.

Gráfico 1. Protagonistas de la noticia.

\section{RESULTADOS Y DISCUSIÓN}

En este apartado vamos a presentar los datos del estudio, organizándolos en dos bloques. Por un lado, analizamos las noticias registradas durante las dos semanas de actividad «normal» de ambos clubes («Semanas normales» en los gráficos) $y$, por otro, analizamos las noticias generadas durante la semana de celebración del derbi («Semana derbi» en los gráficos), por constituir esta una semana excepcional debido al mayor seguimiento informativo realizado a ambos equipos.

En total se registraron 167 minutos y 53 segundos de información. El análisis del tiempo de duración de las noticias nos permitió comprender hasta qué punto estas se encuentran estandarizadas por los protocolos de redacción, presentando tiempos muy similares de atención a los dos equipos. Un ejemplo de ello es el tiempo total de protagonismo de ambos clubes, que, en las «semanas normales», es de un 50,7\% para la UDLP y de un $46,6 \%$ para el CDT.

En el gráfico 1 se recoge el porcentaje de noticias que protagoniza cada club respecto a cada bloque de análisis. El hecho de que la suma de los porcentajes sea superior al $100 \%$ es debido a que hay un conjunto de noticias (44) en la que ambos clubes son protagonistas al mismo tiempo. Durante las semanas «normales» se aprecia un gran esfuerzo por parte del ente por equilibrar la presencia y visibilidad de los dos equipos de referencia. Este es uno de los principales resultados extraídos del estudio. Este equilibrio no es azaroso, sino que forma parte del desempeño profesional en un contexto presionado por la búsqueda de la armonía territorial y el espectro del insularismo. Por su parte, durante la semana del derbi se produce un des- 


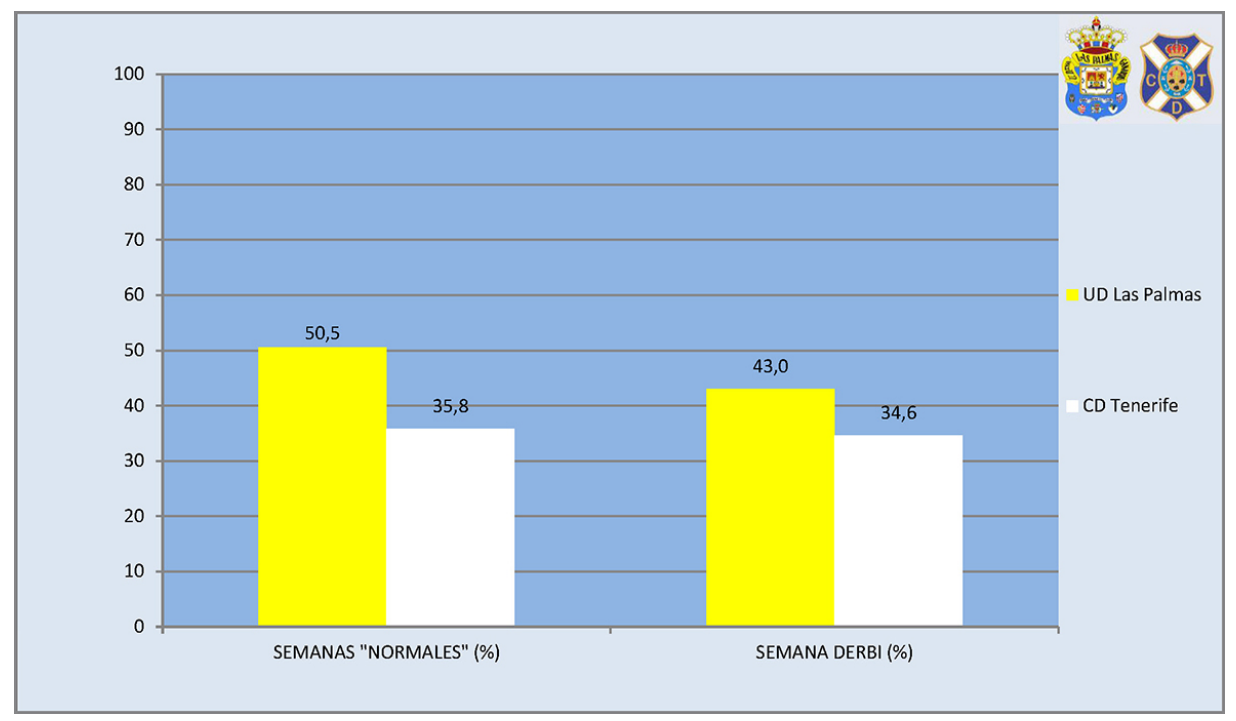

Número de noticias. N= 95 (semanas normales) y N= 107 (semana derbi). Elaboración propia.

Gráfico 2. ¿Por quién se empieza?

equilibrio en el protagonismo a favor de la UDLP, lo que resultaba previsible dada su condición de local en el encuentro.

En el gráfico 2 se presentan los datos sobre "por quién se empieza» en cada noticia. Lo que aquí se valora es el orden de aparición, lo que, sin duda, tiene un impacto sobre los espectadores. Si hay un campo en el que el orden es relevante, ese es el de la comunicación. Por ello, podemos decir que, en este asunto, el orden de los factores sí altera el producto.

En los datos observamos que la UDLP aparece en primer lugar en un mayor número de ocasiones y en ambos bloques de análisis. Sin embargo, en contra de lo que esperábamos (a priori suponíamos que la semana del derbi tendría el efecto tanto de aumentar el protagonismo como el de aumentar el número de veces que las noticias comenzaron por la UDLP, al ser el equipo local), la semana del derbi reduce en cierta medida las diferencias en lo que se refiere a esta cuestión. Una posible explicación a este descenso tiene que ver con las noticias que, durante esa semana, se inician con el tratamiento del desplazamiento de la afición visitante (en este caso la del CDT) y con la presencia de noticias autorreferenciales (la propia TVC se convierte en un protagonista más de la información al generar noticias sobre la cobertura del evento).

Si intentamos dar respuesta a por qué la UDLP aparece más veces en primer lugar nos encontramos con lo que hemos denominado "celo de compensación». Este concepto tiene que ver con la estructura dual de producción de los informativos de la TVC. Los informativos analizados en esta investigación se realizan en la isla de Tenerife y por profesionales de esa misma isla, lo que puede conducir a 


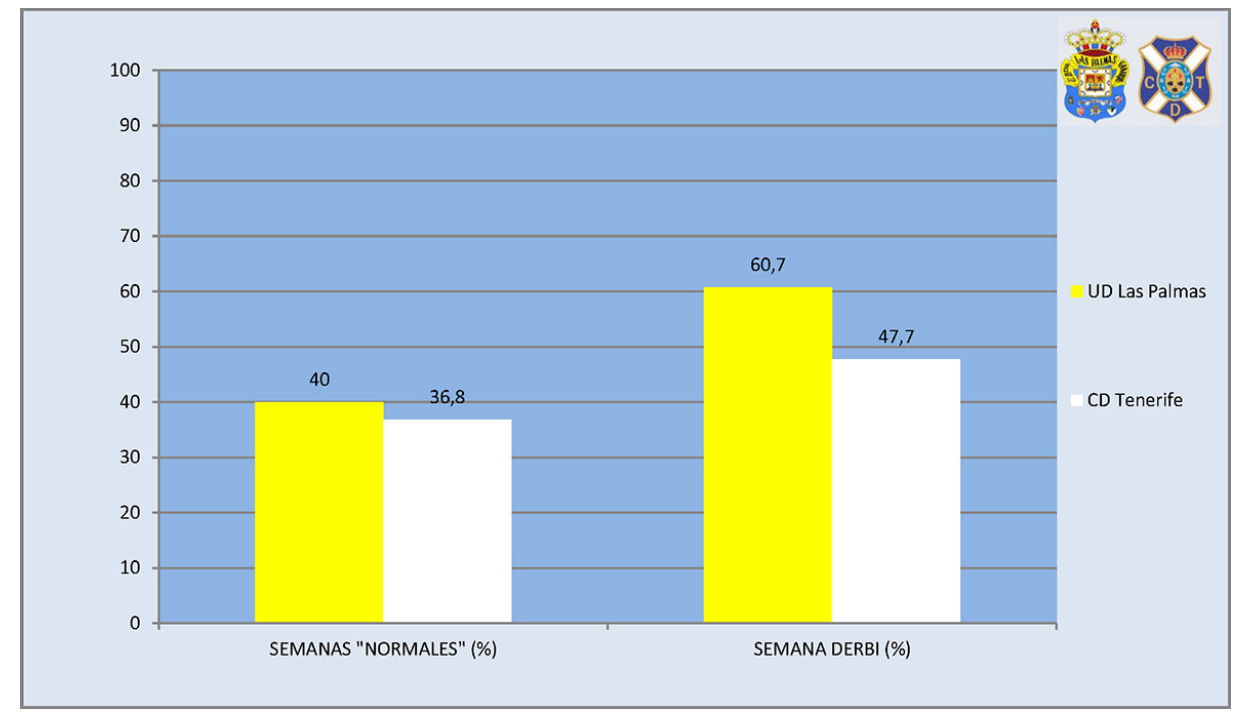

Número de noticias. N= 95 (semanas normales) y N= 107 (semana derbi). Elaboración propia.

Gráfico 3. ¿A quién vemos?

un efecto compensatorio que lleva a presentar en primer lugar la información de la UDLP, para evitar así cualquier acusación de parcialidad. Nuestro entrevistado nos lo explica con mayor claridad:

Sabes que creo que sí influye y lo hemos hablado, y creo que lo hemos corregido, sobre todo que en el presentador o el editor que presenta y escribe las noticias es consciente de que es tinerfeńo y a lo mejor se ve obligado a hacer un esfuerzo en relación hacia el otro club para tratar de equilibrar su condición de tinerfeño, y el grancanario lo mismo, y eso lo he padecido yo en mis propias carnes. Y a lo mejor por esa razón, trabajando en TVC y siendo de Tenerife, trates de darle más importancia a Las Palmas. A lo mejor eso sí ha podido ocurrir ${ }^{13}$.

En el gráfico 3 se presenta el protagonismo en imágenes de cada uno de los equipos. Hablamos aquí no de lo que se cuenta en la noticia, sino de lo que se muestra en la pantalla. Al analizar los datos encontramos un esfuerzo del medio por equilibrar la presencia en imágenes de ambos clubes, aunque la UDLP se encuentra de nuevo ligeramente por encima. La semana del derbi provoca un mayor número de imágenes de ambos clubes, pero en especial de la UDLP, lo que resulta lógico dado que el evento deportivo se produce en su propio estadio (información sobre el

13 Responsable de la sección de deportes de la TVC. Entrevista realizada por los autores, 29 enero 2015. 


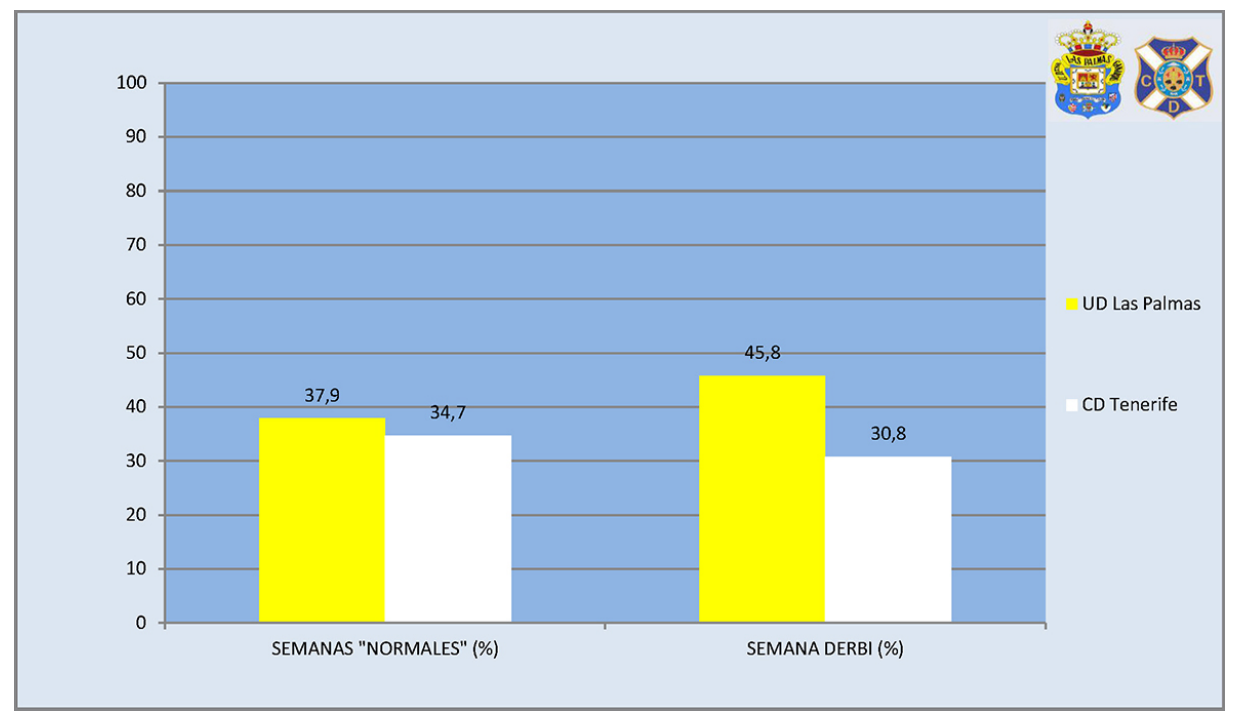

Número de noticias. N= 95 (semanas normales) y N= 107 (semana derbi). Elaboración propia.

Gráfico 4. ¿¿A quién vemos primero?

lugar del acontecimiento, proliferación de panorámicas del estadio, estado del césped, venta de entradas, etc. $)^{14}$.

En el gráfico 4 seguimos con las imágenes, pero esta vez analizamos el orden de aparición. En cuanto a las semanas "normales", se aprecia nuevamente la búsqueda del equilibrio, aunque la UDLP aparece una vez más ligeramente por encima. Con respecto a la semana del derbi sí, encontramos diferencia en relación con el orden de aparición en las noticias que vimos en el gráfico 2. Al contrario de lo que allí sucedía, aquí sí aumenta la diferencia a favor de la UDLP, por las razones asociadas a la localía ya descritas en el gráfico anterior.

En el gráfico 5 tratamos de afinar el análisis ciñéndonos solo a aquellas noticias que podemos considerar más relevantes, las que constituyen el sumario y los cebos. El sumario es un primer avance que se realiza al inicio del informativo general como anticipo de los contenidos que se tratarán en el informativo de deportes. El cebo es un segundo avance de contenidos deportivos que se realiza en la parte final del informativo general con el fin de conectar a la audiencia entre los dos informativos.

${ }_{14}$ En total se registraron 134 minutos y 29 segundos de imágenes. En este apartado el equilibrio también se deja ver muy claramente. Por ejemplo, en las semanas de actividad «normal» el porcentaje de tiempo que la UDLP protagoniza las imágenes es de un $46,9 \%$, mientras que el CDT lo hace en un $46 \%$. 


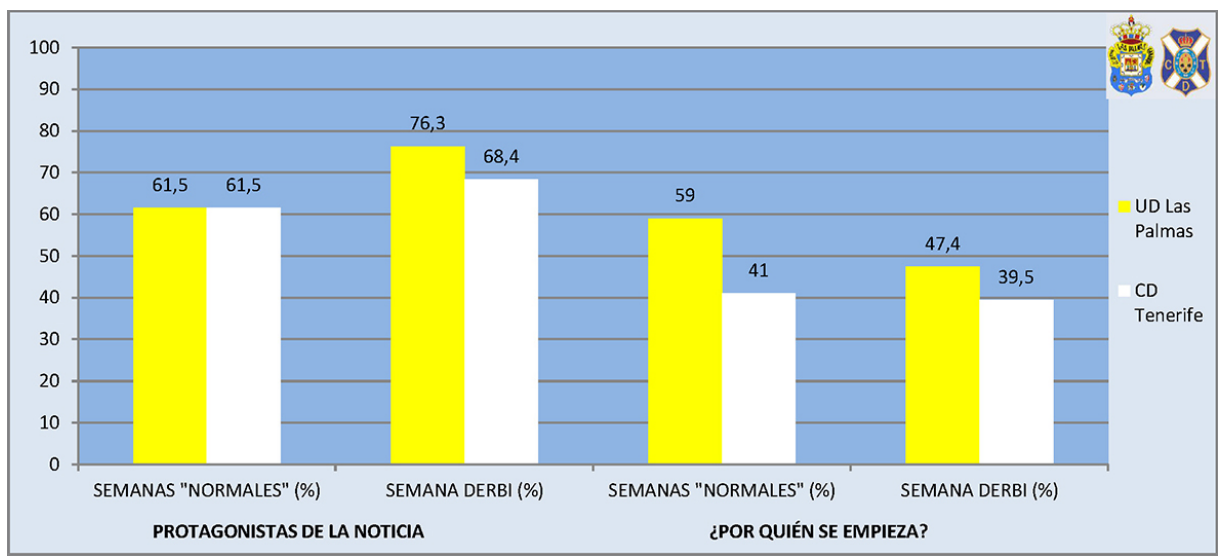

Número de noticias. $\mathrm{N}=39$ (semanas normales) y $\mathrm{N}=38$ (semana derbi). Elaboración propia.

Gráfico 5. Noticias de sumario y cebo.

En cuanto al protagonismo, en las semanas «normales» encontramos un perfecto equilibrio entre los dos clubes, mientras que en la semana del derbi se aprecia una mayor preeminencia de la UDLP. Estos datos mantienen una lógica similar a los que vimos en el gráfico 1 . Por su parte, si atendemos al orden de aparición, también encontramos correspondencia entre este corte de análisis y los datos de conjunto que vimos en el gráfico 2. La UDLP aparece en primer lugar un mayor número de veces en ambos bloques, siendo menores las diferencias en la semana del derbi. Confirmamos así la doble lógica de la semana del derbi, que aumenta el protagonismo de la UDLP al tiempo que reduce las diferencias en cuanto al orden de aparición.

En el gráfico 6 indagamos en torno a lo que hemos denominado "protagonismo y prelación fuerte», limitándonos a observar exclusivamente la primera noticia deportiva del sumario del informativo general y la primera noticia del informativo de deportes. Se trata de analizar el protagonismo y orden de aparición iniciales, entendiendo que ese grupo de noticias tiene un especial impacto sobre la atención del espectador.

Lo que encontramos es que en este corte se da, para las semanas «normales», la mayor diferencia en cuanto al protagonismo de ambos clubes de entre todos los agrupamientos analizados. La UDLP protagoniza las primeras informaciones en más ocasiones que el CDT (21 noticias frente a 16$)^{15}$. Sin embargo, en lo refe-

${ }^{15}$ Los agrupamientos analíticos presentados en los gráficos 6 y 7 cuentan con un tamaño de muestra sensiblemente más pequeño que en el resto de los casos, lo que nos obliga a valorar con precaución las diferencias obtenidas en los porcentajes. Por ello hemos optado por introducir en la explicación el número exacto de noticias que corresponden a cada club en cada caso. 


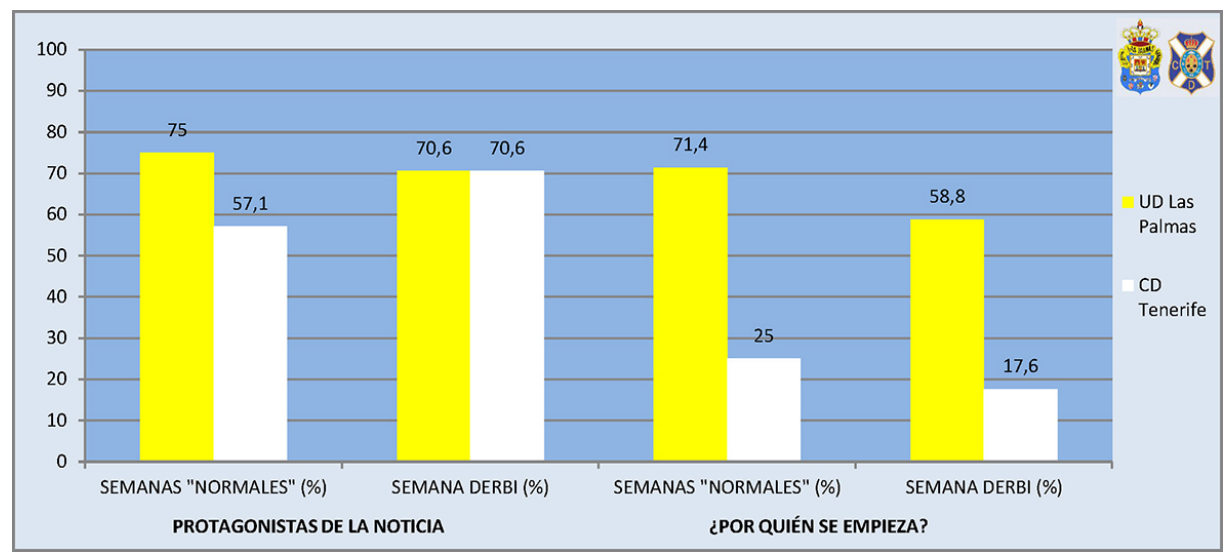

Número de noticias. $\mathrm{N}=28$ (semanas normales) y N=17 (semana derbi). Elaboración propia.

Gráfico 6. Protagonismo y prelación fuerte: primer sumario y primera noticia.

rente a la semana del derbi vemos un total equilibrio entre ambos clubes (12 a 12), debido fundamentalmente al elevado número de noticias de protagonismo compartido. En cuanto al orden de aparición, la diferencia aumenta a favor de la UDLP (20 noticias frente a 7 en las semanas «normales» y 10 a 3 en la semana del derbi).

Este corte analítico es sumamente importante porque confirma las tendencias apuntadas en el conjunto de los datos revisados. En cuanto al protagonismo, nos ayuda a visibilizar que, dentro de la tónica general de equilibrio, existe una mayor presencia de la UDLP, efecto que no se aprecia de forma tan clara en las agrupaciones de datos anteriores. En cuanto al orden de aparición, también se profundiza en las diferencias a favor de la UDLP, mucho mayores que las vistas hasta el momento.

En el gráfico 7, para cerrar el análisis, nos detenemos a explorar solo las noticias en las que ambos clubes comparten protagonismo. Se trata de ver por qué equipo se empieza cuando en una misma noticia se habla de los dos clubes. Lo que vemos es que una vez más se confirma la dominancia de la UDLP. Y esto se produce tanto si contemplamos las semanas «normales» (9 noticias frente a 1) como si atendemos a la semana del derbi (21 a 13). Por lo tanto, no se puede explicar esa dominancia a partir de la condición de local de la UDLP en el derbi acontecido.

En toda la información presentada y dado lo complejo de los productos culturales producidos, dos fuerzas se ven reflejadas en el conjunto del análisis. La primera es el esfuerzo del medio por equilibrar, en tiempos, orden, noticias, etc., la presencia informativa de los dos representativos canarios en un contexto de tensión insularista y competencia por las audiencias (hay que tener en cuenta que, según nos contó nuestro entrevistado, en los informativos Telenoticias 2 y TN Deportes 2, incluidas sus ediciones de fin de semana, se invierte sistemáticamente el orden de inicio de la información deportiva entre los dos clubes, como forma de buscar el equilibrio). 


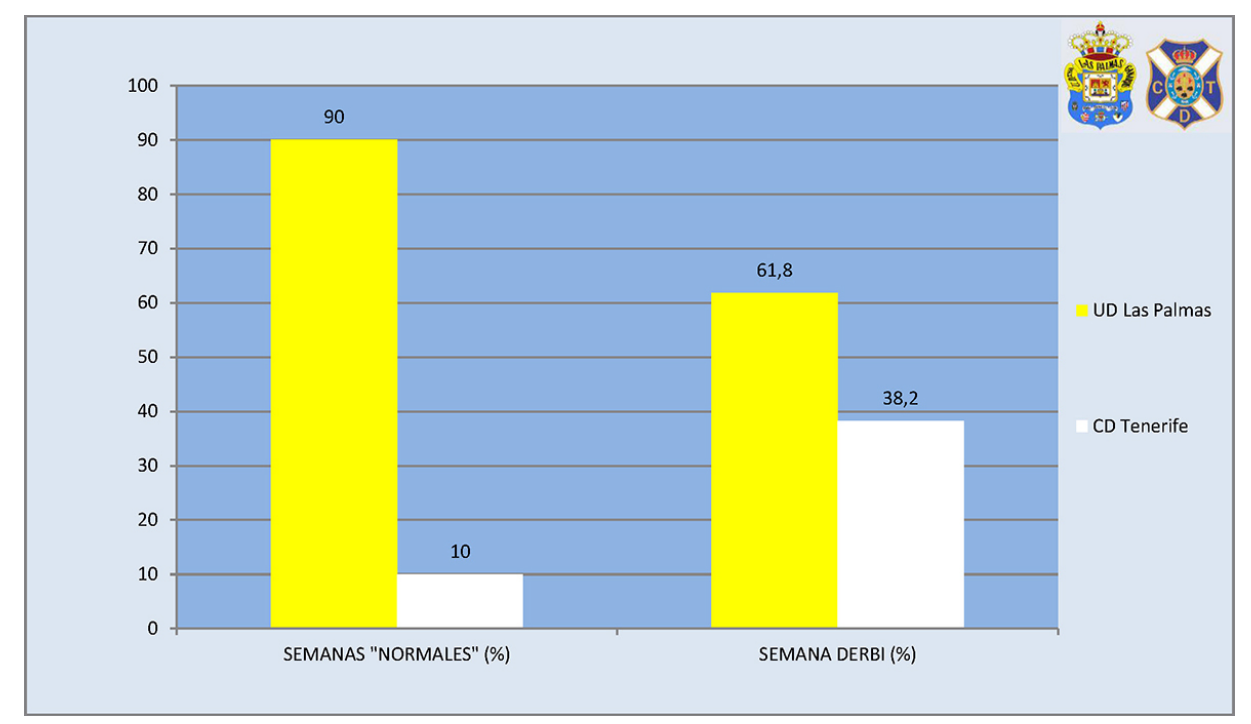

Número de noticias. $\mathrm{N}=10$ (semanas normales) y $\mathrm{N}=34$ (semana derbi). Elaboración propia.

Gráfico 7. Cundo se habla de los dos, ¿por quién se empieza?

Dentro de las medidas que hemos mecanizado para tratar de distribuir el tiempo de manera ecuánime entre los dos equipos es que invertimos el orden [...]. Normalmente, en el Telenoticias 2 del mismo día cambia el orden. Si el primer sumario es de Las Palmas, en el Telenoticias 2 es del Tenerife [...]. Si el estudio se hubiese ampliado al Telenoticias 2, probablemente nos habríamos encontrado, en cuanto a primera noticia de sumario y primera noticia de bloque, un resultado más equilibrado. Es lo que solemos hacer, lo hacemos a diario y lo pueden comprobar ustedes hoy mismo. Si en el 1 se abre con un equipo en el 2 se abre con el otro, que está hecho justamente para corregir cualquier tendencia ${ }^{16}$.

En este trabajo no se han analizado los informativos de la segunda edición, lo que nos impide comprobar si ese esfuerzo de compensación es tal y como nos lo cuenta el responsable de la TVC. Aun siendo así, el informativo de la segunda edición, como hemos visto, mantiene audiencias significativamente más bajas que el de la primera, ya que compite con el prime time de las principales cadenas estatales. Por lo tanto, el efecto compensatorio de esta estrategia sería, en todo caso, débil.

La segunda fuerza detectada tiene que ver con la persistente y consistente preeminencia de la UDLP en el conjunto de los datos. Aunque la diferencia es

${ }^{16}$ Responsable de la sección de deportes de la TVC. Entrevista realizada por los autores, 29 enero 2015. 
pequeña y prima el equilibrio, las diferencias a favor de esta son recurrentes, especialmente en cuanto al orden de aparición y en los análisis en los que focalizamos la atención sobre el «protagonismo fuerte». Como a través de la entrevista hemos descartado la existencia del criterio clasificatorio para presentar y ordenar la información (existente solo en las primeras etapas de la cadena), las explicaciones para este fenómeno pueden ser varias, como el efecto "celo de compensación» o el estado de las relaciones con los clubes. Sin embargo, resulta extremadamente complejo determinar qué conjunto de elementos y con qué proporción están influyendo en estos resultados de manera concreta.

\section{CONCLUSIONES}

Como conclusión diremos que la resultante informativa futbolística de la TVC es producto de la defensa del pluralismo restringido a los dos grandes equipos de fútbol regionales y a una autorregulación estricta, salpicada de componentes de edición precisa y de calculada autocensura en ocasiones superada por la improvisación del directo ${ }^{17}$. La resultante es un equilibrio en su producción en el que la UDLP se sitúa, en prácticamente todas las variables analizadas, unos puntos por encima. En cuanto a la lógica de la semana del derbi apreciamos un aumento del protagonismo del equipo local, así como una cierta disminución de las diferencias en cuanto al orden de aparición de ambos clubes. Para precisar el «efecto derbi» esto debería ser contrastado mediante un análisis comparado con un derbi en el que el CDT ejerciera como local, cosa que no se ha hecho en este trabajo.

Podemos decir también que para la TVC es imposible escapar a la ideología del victimismo que construyen las audiencias-aficionados. Este artículo no podrá resolver el dilema. No obstante, el gran esfuerzo de purificación política, de neutralidad afectiva y de intento de equilibrio en el tratamiento informativo mantiene, hasta cierto punto, a salvo el fútbol del pleito insular, aunque no del pleito futbolístico.

El fútbol participa de un mercado informativo particular en el que el entretenimiento y la pasión se suelen anteponer a la veracidad y la precisión informativa. En un mercado informativo competido, con medios especializados, en el que cada vez gana más terreno la propaganda a la información, el peaje que la TVC paga por no seguir esta estrategia es enorme. La precisión informativa, comedida y neutra afectivamente, en un marco de rivalidad deportiva regional, aleja al ente auto-

${ }^{17}$ La improvisación del directo la pudimos experimentar el 22-06-2014 en el tratamiento informativo dado al partido entre la UDLP y el Córdoba Club de Fútbol, que dirimía el ascenso a Primera División de uno u otro club. En los minutos finales del mismo, cuando la UDLP ganaba 1-0, se produjo una invasión de campo por parte de algunos de sus aficionados, lo que provocó la suspensión momentánea del partido. En la reanudación el Córdoba anotó el empate, logrando el ascenso y generando una situación de gran tensión en el estadio. Ahí, la TVC y sus periodistas se vieron inmersos en un contexto de fuerte contenido emocional, atravesando las líneas habituales de autocontención. 
nómico de los modelos postperiodistas que se están generando y que se basan en la cultura de la exaltación pasional.

Cualquier lógica deontológica o intento de regulación de equivalencias será siempre disputada. Puede que el medio gane su batalla con la purificación entre fútbol y política, pero en este mismo acto tiende a perder su conexión con las audiencias-aficionados generando escenarios de deseconomización del medio y distancia afectiva de su audiencia potencial. Todo lo contrario de productos en los que la efervescencia informativa se liga al descrito ya como postperiodismo, basado más en el espectáculo y el entretenimiento (un ejemplo ilustrativo de esto lo tenemos en la cadena nacional Cuatro con su Deportes Cuatro).

En definitiva, a la luz de los datos obtenidos, los aficionados del CDT parecen tener más fundamento para la queja sobre la TVC que los de la UDLP. Aunque, cuando se trata de la cultura de la queja, las razones de las víctimas son siempre difíciles de baremar, objetivo que este artículo no se proponía alcanzar.

Recibido: 12 de abril de 2019, aceptado: 10 de julio de 2019 


\section{BIBLIOGRAFÍA}

Acirón Royo, R. (1998). Canarias: prensa y política: crónica periodística sobre el autogobierno y la transición democrática en las islas. Canarias: Gobierno de Canarias.

Aguado, G. (1994). «Treinta años de TVE en Canarias». Disenso: Revista canaria de análisis y opinión, 6: 6.

Aguilera Klink, F. (2004). «¿Nacionalismo o subvencionalismo? Reflexiones sobre el modelo canario de victimismo económico». Disenso: Revista canaria de análisis y opinión, 42: 36-37. Disponible en http://www.pensamientocritico.org/fedagu0304.htm.

Aznar, H. (2005). Comunicación responsable. La autorregulación de los medios. Barcelona: Ariel.

Ball, P. (2010). Morbo. La historia del fútbol español. Madrid: T \& B.

Bassets, Ll. (2013). El último que apague la luz. Sobre la extinción del periodismo. Madrid: Taurus.

Bustamante Ramírez, E. (2006). Radio y televisión en España: historia de una asignatura pendiente de la democracia. Barcelona: Gedisa.

Club Deportivo Tenerife [web en línea]. Consultada el 6 de marzo de 2015 desde http://www. clubdeportivotenerife.es.

Debord, G. (1976). La sociedad del espectáculo. Madrid: Castellote.

Elias, N. (1989). El proceso de civilización. Investigaciones sociogenéticas y psicogenéticas. México: Fondo de Cultura Económica.

Elias, N. y Dunning, E. (1992). Deporte y ocio en el proceso de civilización. México: Fondo de Cultura Económica.

Gallardo Parrón, R. y Montes Vozmediano, M. (2015). «La propiedad de los derechos de emisión de los eventos deportivos y su repercusión en los informativos: el caso de Antena 3, La 1 y Telecinco». Fonseca-Journal of Communication, 10: 9-28. Disponible en http://revistas.usal. es/index.php/2172-9077/article/view/12909/13282.

Gobierno de Canarias [web en línea]. Consultada el 13 de marzo de 2015 desde http://www. gobiernodecanarias.org/hacienda/dgplani/presupuestos/.

GonzÁlez Radío, V. (1997). La sociedad mediática. A Coruña: Universidade da Coruña.

González Ramallal, M. (2004a). «El reflejo del deporte en los medios de comunicación en España». Revista Española de Sociología, n. ${ }^{\circ}$ 4: 271-280. Disponible en http://www.fes-sociologia. com/files/res/4/12.pdf.

González Ramallal, M. (2004b). Sociedad y deporte: análisis del deporte en la sociedad y su reflejo en los medios de comunicación. Tesis doctoral inédita, Universidad de A Coruña. Disponible en http://www.tesisenred.net/TDR-0425106145348/index_cs.html.

González Ramallal, M. (2014). «Prensa deportiva e identidad nacional: España en el Mundial de fútbol de Sudáfrica 2010». Politica y Sociedad, n. 54 (2): 337-366. Disponible en http:// revistas.ucm.es/index.php/POSO/article/view/43077/43669.

González Ramallal, M., Castilla, J.L. y Mesa, A. (2014). «Postmodern footballers and their "second skin": emotional narratives ranging from solidarity to intimacy». Soccer \& Society, n. ${ }^{\circ} 16$ (4): 437-452. DOI: http://dx.doi.org/10.1080/14660970.2014.882827.

Guimerá Peraza, M. (2011). El pleito insular (1808-1936). Tenerife: Cabildo de Tenerife.

Kapuscinski, R. (2006). Los cinicos no sirven para este oficio. Barcelona: Anagrama. 
Liga de Fútbol Profesional [web en línea]. Consultada el 15 de marzo de 2015 desde http:// www.lfp.es/.

Llopis Goig, R. (2006a). «Clubes y selecciones nacionales de fútbol. La dimensión etnoterritorial del fútbol español». Revista Internacional de Sociologia, 45: 37-66. Disponible en http:// revintsociologia.revistas.csic.es/index.php/revintsociologia/article/viewFile/15/15.

LLopis Goig, R. (2006b). «El fútbol como ritual festivo. Un análisis referido a la sociedad española». Revista Andaluza de Ciencias Sociales, 6: 115-132. Disponible en https://dialnet.unirioja.es/ descarga/articulo/2519996.pdf.

López-González, H., Guerrero-Solé, F. y Larrea, O. (2014). «Community building in the digital age: Dynamics of online sports discussion». Communication \& Society, 27(3): 83-105. Disponible en http://www.unav.es/fcom/communication-society/descarga_doc.php?art_id=502.

Montero, M.Á. (2014). «La Televisión Canaria recibirá más dinero en 2015 pese a la caída presupuestaria». $A B C$. Consultada el 14 de enero de 2015 desde http://www.abc.es/local-canarias/20141105/abci-television-canaria-presupuesto-201411042200.html.

Monzón, M.E. y Santana, J.M. (1988). La pugna intracanaria. Canarias: Unión de Nacionalistas de Izquierda.

Palacio, M. (2001). Historia de la televisión en España. Barcelona: Gedisa.

Riera, F. (2003). «La post-televisión: de la televisión antropológica a la sociedad digital». Quaderns del CAC, 15: 93-96. Disponible en https://www.cac.cat/web/recerca/quaderns/hemeroteca/ detall.jsp?NDg\%3D\&Mg\%3D\%3D\&Jyc\%3D\&OA\%3D\%3D.

RTVC.es [web en línea]. Consultada el 10 de febrero de 2015 desde http://www.rtvc.es/corporativa/ cronologia.aspx.

Ruiz, J. (2009). «Análisis sociológico del discurso: métodos y lógicas». Forum Qualitative Sozialforschung, 10(2), art. 26. Disponible en http://www.qualitative-research.net/index.php/fqs/ article/view/1298/2776.

Sánchez, A. (1983). Ensayos sobre la cultura canaria. Las Palmas de Gran Canaria: Edirca.

Unión Deportiva Las Palmas [web en línea]. Consultada el 6 de marzo de 2015 desde http:// www.udlaspalmas.es/. 
